\title{
ANALISIS PENERAPAN METODE POHON BINOMIAL DAN METODE BLACK-SCHOLES DALAM PENENTUAN HARGA OPSI BELI
}

\author{
Betty Subartini', Riaman'2, Nahda Nabiilah ${ }^{3}$, Sukono $^{4}$ \\ 1,23,4 Universitas Padjadjaran, Jl. Raya-Bandung-Sumedang km 21 Jatinangor Sumedang, Indonesia \\ Email: betty.subartini@unpad.ac.id
}

\begin{abstract}
An option is one of the letters of agreement to buy and sell shares between the seller and the buyer to agree with the specified price and period. A person who buys an option can choose to exercise his or her rights or not. This research aims to find out the results of the price comparison of Apple Inc.'s Buy Options, with the use of two methods, namely the Binomial Tree method and the Black-Scholes method. The results of this study show that assuming the risk-free interest rate and the specified strike price are the same, the results of the calculation of the price of the Buy Option with both methods are almost the same. It can be concluded that the price of The Buy Option obtained by the Binomial Tree method is close to the price of the Buy Option with the Black-Scholes method. So that both methods are worth using for the initial calculation of the price of the Buy Option.
\end{abstract}

Keywords: Black-scholes method, binomial tree method, european type option

\section{ABSTRAK}

Opsi adalah salah satu surat perjanjian jual beli saham antara pihak penjual dan pembeli untuk melakukan suatu kesepakatan dengan harga dan periode yang ditentukan. Seseorang yang membeli opsi bisa memilih untuk melaksanakan haknya ataupun tidak. Penelitian ini bertujuan mengetahui hasil perbandingan harga Opsi Beli Apple Inc., dengan penggunaan dua metode yaitu metode Pohon Binomial dan metode Black-Scholes. Hasil dari penelitian ini menunjukkan bahwa dengan asumsi suku bunga bebas risiko dan strike price yang ditentukan sama, maka hasil perhitungan harga Opsi Beli dengan kedua metode tersebut hampir sama. Dapat disimpulkan bahwa harga Opsi Beli yang didapat dengan metode Pohon Binomial mendekati harga Opsi Beli dengan metode Black-Scholes. Sehingga kedua metode tersebut layak digunakan untuk perhitungan awal harga Opsi Beli.

Kata kunci: Metode black-scholes, metode pohon binomial, opsi tipe eropa

Dikirim: 31 Juli 2021; Diterima: 08 September 2021; Dipublikasikan: 30 September 2021

Cara sitasi: Subartini, B., Riaman, Nabiliah, N., \& Sukono. (2021). Analisis penerapan metode pohon binomial dan metode blackscholes dalam penentuan harga opsi beli. Teorema: Teori dan Riset Matematika, 6(2), 260-266. DOI: http://dx.doi.org/10.25157/teorema.v6i2.5781 


\section{PENDAHULUAN}

Harga saham yang terus berubah tentunya menyebabkan seorang pembeli khawatir terhadap risiko yang akan ditanggung jika harga saham turun pada saat akan dijual. Oleh karena itu ada salah satu turunan saham yang dapat mengurangi risiko yaitu opsi. Opsi adalah sebuah perjanjian jual beli saham antara pihak penjual opsi (writer), dan pihak pembeli opsi (holder) dengan harga kesepakatan (strike price) dan pada periode yang ditentukan. Pemilik opsi memiliki hak untuk menjual opsi tersebut atau tidak, selama masa waktu jatuh tempo belum berakhir. Ada beberapa tipe opsi diantaranya tipe Eropa dan tipe Amerika, yang membedakannya adalah dalam proses penjualan opsi (exercise), untuk tipe Eropa, exercise hanya pada saat jatuh tempo, sedangkan tipe Amerika exercise dapat dilakukan pada periode-periode tertentu sebelum masa waktu yang telah ditentukan berakhir(maturity time) (Hull, 2012).

Penelitian sebelumnya telah dibahas mengenai "Kelebihan dan Kekurangan Metode Pohon Binomial" oleh Emmanuel et al., (2014). Kemudian Harga Opsi Beli dengan Metode Black-Scholes dibandingkan dengan Harga Opsi Beli Sebenarnya oleh (Krznaric, 2016), selain itu juga ada yang membahas tentang Penerapan Model Matematika dalam Bidang Keuangan Khususnya Bidang Ekonomi yang dikemukakan oleh Sulaiman et al., (2017). Oleh karena itu, penulis termotivasi untuk melakukan pengembangan dalam penentuan harga opsi beli, apabila digunakan metode Pohon Binomial dengan Metode Black-Scholes, kemudian dianalisis hasil perhitungannya, selain itu yang menjadi alasan pemilihan dalam membahas masalah tersebut adalah belum ada peneliti sebelumnya yang membahas hal tersebut, sehingga hasil yang diperoleh dapat digunakan sebagai pertimbangan dalam pemilihan metode apa yang terbaik dalam penentuan harga beli opsi.

\section{METODE PENELITIAN}

Metode Pohon Binomial dan Black-Scholes adalah dua metode yang digunakan dalam penelitian ini, dengan tujuan menghitung harga Opsi Beli pada Apple Inc. (AAPL). Data dalam penelitian ini diperoleh dari harga penutupan saham Apple Inc dari tanggal 1 Januari 2019 sampai 31 Desember 2019 dan strike price diperoleh dari yahoo finance, sedangkan tingkat suku bunga bebas risiko $(r)$ diperoleh dari www.treasury.gov. Alat bantu perhitungan digunakan Microsoft Excel dan Dev C++ untuk program $\mathrm{C}++$.

Penelitian ini terlebih dahulu penentuan nilai volatilitas saham yaitu ketidakpastian dari pergerakan saham. Nilai volatilitas $(\boldsymbol{\sigma})$ berada di interval $\mathbf{0} \leq \boldsymbol{\sigma} \leq \infty$. Volatilitas yang rendah berarti harga saham cenderung stabil, sementara volatilitas yang tinggi berarti harga saham tidak stabil dan memiliki banyak risiko (Hull, 2012). Volatilitas bisa dihitung dengan langkah berikut:

(1) Menghitung return harga saham dengan persamaan:

d

$$
R_{t}=\ln \left(\frac{s_{t}}{s_{t-1}}\right)
$$

ngan $S_{t}$ : harga saham pada akhir interval $t,(t=1,2,3, \ldots)$

(2) Menghitung $\overline{R_{t}}$, yaitu expected return dengan persamaan:

dengan $n$ : jumlah data.

$$
\overline{R_{t}}=\frac{\sum_{t=1}^{n} R_{t}}{n}
$$

(3) Menghitung volatilitas dengan persamaan:

$$
\sigma=\sqrt{\frac{1}{n-1} \sum_{t=1}^{n}\left(R_{t}-\overline{R_{t}}\right)^{2} \cdot k}
$$

dengan $\sigma$ : volatilitas dan $k$ : Jumlah periode perdagangan (Harian, $k=252$ ) (Hull, 2012). 
Setelah penentuan nilai volatilitas dilakukan Uji normalitas dengan Chi-Squared Uji Chi-Squared untuk uji normalitas didefinisikan dengan hipotesis:

$H_{0}$ : Data berdistribusi normal

$H_{\alpha}$ : Hipotesis alternatif, yaitu data tidak berdistribusi normal

Langkah yang dilakukan untuk uji ini adalah:

(1) Membuat bin atau pengelompokan data sejumlah $k$.

(2) Mencari frekuensi setiap bin dengan bantuan data analysis di Microsoft Excel.

(3) Menghitung ekspektasi setiap bin $\left(E_{i}\right)$, dengan persamaan:

$$
E_{i}=\left(N\left(F\left(Y_{i+1}\right)-F\left(Y_{i}\right)\right)\right.
$$

dengan $N$ : jumlah data, $Y_{i}$ : nilai dari bin $i(i=1,2,3, \ldots, k)$, dan $F\left(Y_{i}\right)$ : fungsi distribusi kumulatif dari $Y_{i}$.

(4) Menghitung nilai Chi-Squared dengan persamaan:

$$
\chi 2=\sum_{i=1}^{k} \frac{\left(O_{i}-E_{i}\right)^{2}}{E_{i}}
$$

dengan $O_{i}$ : frekuensi data yang di observasi untuk bin ke-i.

(5) Menghitung derajat kebebasan dengan persamaan:

$$
d k=k-c-1
$$

dengan $c$ : jumlah parameter. Dalam uji normalitas, $c=2$

(6) Menghitung $p$-value dari nilai $\chi^{2}$ yang didapat dengan bantuan CHISQ.DIST.RT dengan Microsoft Excel.

(7) Ambil kesimpulan. Hipotesis $\left(H_{0}\right)$ dari data akan ditolak jika $p$-value hitung $<0.05$

\section{Metode Pohon Binomial}

Metode Pohon Binomial mengasumsikan bahwa harga saham sekarang hanya bisa naik atau turun dalam setiap periodenya (Cox et al., 1979).

Untuk menghitung harga Opsi Beli dengan metode Pohon Binomial menurut Hull (2012) dilakukan langkah berikut :

(1) Menghitung $u$, dan $d$ pada metode Pohon Binomial dengan persamaan:

$$
\begin{aligned}
& u=e^{\sigma \sqrt{\Delta t}} \\
& d=e^{-\sigma \sqrt{\Delta t}}=\frac{1}{u}
\end{aligned}
$$

dengan $u$ : faktor naik, $d$ : faktor turun, $\sigma$ : volatilitas, dan $\Delta t$ : time to expiry.

(2) Menghitung $C_{u}$ dan $C_{d}$ dengan persamaan:

$$
\begin{aligned}
& C_{u}=\operatorname{Max}(0, S \cdot u-K) \\
& C_{d}=\operatorname{Max}(0, S \cdot d-K)
\end{aligned}
$$

dengan $C_{u}$ : payoff ketika nilai saham naik, dan $C_{d}$ : payoff ketika nilai saham turun.

(3) Menghitung nilai $p$ dengan persamaan:

dengan $r$ : tingkat bunga bebas risiko.

$$
p=\frac{e^{r \Delta t}-d}{u-d}
$$

(4) Menghitung nilai $C$, yaitu harga Opsi Beli dengan persamaan:

$$
=\frac{\left(p \cdot C_{u}\right)+\left((1-p) \cdot\left(C_{d}\right)\right)}{i}
$$

dengan $i=1+r$.

\section{Metode Black-Scholes}

Metode Black-Scholes mengasumsikan bahwa harga saham sekarang hanya bisa naik atau turun dalam setiap periodenya (Cox et al., 1979)

Untuk menghitung harga Opsi Beli dengan metode ini, langkah yang dilakukan adalah:

(1) Menghitung $d 1$ dan $d 2$ dengan persamaan: 


$$
\begin{aligned}
& d 1=\frac{\ln \left(\frac{S_{0}}{K}\right)+\left(r+\sigma^{2} / 2\right) \cdot t}{\sigma \sqrt{t}} \\
& d 2=d 1-\sigma \sqrt{t}
\end{aligned}
$$

dengan $S_{0}$ : harga saham sekarang, $K$ : harga kesepakatan (strike price), $r$ : suku bunga, dan $t$ : time to expiry (tanggal kadaluarsa).

(2) Menghitung $N(d 1)$ dan $N(d 2)$, di mana $N(d 1)$ : fungsi distribusi kumulatif dari $d 1$, dan $N(d 2)$ : fungsi distribusi kumulatif dari $d 2$. Perhitungan dilakukan dengan bantuan NORM.DIST di Microsoft Excel.

(3) Menghitung nilai Opsi Beli $(C)$ dengan persamaan:

$$
C=S_{0} N(d 1)-K e^{-r t} N(d 2)
$$

Nilai awal yang dinputkan adalah harga saham sekarang $(\boldsymbol{S})$ yang digunakan adalah nilai close terakhir $(\boldsymbol{N}=$ 250 ) sebesar $\$ \mathbf{2 9 1}$. 52, nilai bunga bebas risiko $(\boldsymbol{r})$ yang digunakan adalah $1.56 \%$, nilai strike price $(\boldsymbol{K})$ yang digunakan adalah $\mathbf{\$ 1 0 5}$, dan trading days $(\boldsymbol{k})$ adalah 326 hari. Semua perhitungan menggunakan bantuan software Microsoft Excel dan program C++.

\section{HASIL DAN PEMBAHASAN}

Penggunaan metode Pohon Binomial dan Metode Black-Scholes harus memenuhi syarat-syarat tertentu diantaranya adalah data harus berdistribusi normal. Data harga penutupan saham Apple Inc. (AAPL) yang diperoleh dari situs Yahoo Finance tersebut diuji normalisasinya menggunakan metode Chi-Squared. Langkah pertama dicari terlebih dulu nilai Return, Expected Return dan nilai Volatilitas berturut-turut menggunakan persamaan. (1), (2), dan (3), perhitungan dibantu Microsoft excel diperoleh nilai expected return $=0.00245208$ dan nilai volatilitas tahunan sebesar 0.300727 .

Langkah kedua dilakukan Uji Normalitas dengan metode Chi-Squared, pertama buat bin, yaitu kelompok data. Dalam penelitian ini, bin terkecil diambil dengan nilai -0.025 , dan interval sebesar 0.0025 . sehingga diperoleh 33 bin. Lalu, dengan bantuan data analysis dari Microsoft Excel, akan diperoleh frekuensi dari setiap bin. Output dari data analysis yang menunjukan frekuensi dari setiap bin, dapat dilihat pada Tabel 1.

Tabel 1. Output bin dan frekuensi

\begin{tabular}{cc}
\hline Bin & Frequency \\
\hline-0.025 & 8 \\
-0.0225 & 2 \\
$\vdots$ & $\vdots$ \\
0.0525 & 0 \\
0.055 & 1 \\
\hline
\end{tabular}

Setelah didapatkan frekuensi setiap bin, hitung $E_{i}$ dengan persamaan (4). Frekuensi yang didapat dari Tabel 1 kemudian akan digunakan sebagai $O_{i}$. $E_{i}$ dan $O_{i}$ dapat dilihat secara singkat pada Tabel 2.

\begin{tabular}{cc} 
Tabel 2. Perhitungan seluruh \\
\hline$E_{i}$ & $O_{i}$ \\
\hline 12.41377822 & 8 \\
4.349359969 & 2 \\
$\vdots$ & $\vdots$ \\
0.206242939 & 0 \\
0.131482634 & 1 \\
\hline
\end{tabular}

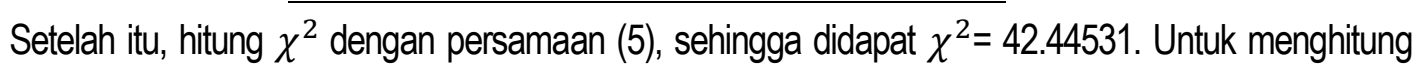
$d k$, gunakan persamaan (6) sehingga didapat $d k=30$. Dengan kedua nilai tersebut, gunakan bantuan CHISQ.DIST.RT pada Microsoft Excel untuk mendapatkan p-value. $P$-value yang didapatkan adalah 0.065521 . Karena $p$-value $=0,065521>0.05$, maka kesimpulannya data berdistribusi normal. 


\subsection{Perhitungan dengan Metode Pohon Binomial}

\subsubsection{Perhitungan menggunakan Metode Pohon Binomial dengan bantuan Microsoft Excel} Tabel 3.

Pertama cari nilai dari $u$ dan $d$ dengan persamaan (7) dan (8). Hasil perhitungannya terlihat pada

Tabel 3. Hasil perhitungan $u$ dan $d$

\begin{tabular}{cccc}
\hline$N$ & Close & $u$ & $d$ \\
\hline 0 & 157.919998 & - & - \\
1 & 142.190002 & 1.016795 & 0.9835 \\
$\vdots$ & $\vdots$ & $\vdots$ & $\vdots$ \\
249 & 289.799988 & 1.300596 & 0.7689 \\
250 & 291.519989 & 1.301282 & 0.7685 \\
\hline
\end{tabular}

Dengan menggunakan persamaan (9) dan (10), lakukan perhitungan $C_{u}$ dan $C_{d}$. Hasil perhitungan dapat dilihat pada Tabel 4.

Tabel 4. Hasil perhitungan $C_{u}$ dan $C_{d}$

\begin{tabular}{cccc}
\hline$N$ & Close & $C_{u}$ & $C_{\mathrm{d}}$ \\
\hline 0 & 157.919998 & 39.57811266 & 34.84133764 \\
1 & 142.190002 & 46.79367722 & 39.80857517 \\
$\vdots$ & $\vdots$ & $\vdots$ & $\vdots$ \\
249 & 289.799988 & 271.9128314 & 117.8208382 \\
250 & 291.519989 & 274.3498098 & 119.0251657 \\
\hline
\end{tabular}

Selanjutnya, gunakan persamaan (11) untuk mencari nilai $p$, dan gunakan persamaan (12) untuk mencari harga Opsi Beli $(C)$ diperoleh hasilnya pada Tabel 5.

Tabel 5. Hasil perhitungan $p$ dan $C$

\begin{tabular}{ccc}
\hline$N$ & $p$ & $C$ \\
\hline 0 & 0.4973 & 36.62544934 \\
1 & 0.4961 & 42.60947714 \\
$\vdots$ & $\vdots$ & $\vdots$ \\
249 & 0.4572 & 185.3817515 \\
250 & 0.4571 & 187.1095336 \\
\hline
\end{tabular}

Tabel 5, menunjukkan bahwa untuk $N=250$ dapat dilihat bahwa nilai $C=187.1095336$., maka dapat disimpulkan bahwa pada saat hari ke- 250 didapat harga opsi beli menggunakan metode Pohon Binomial adalah sebesar \$187,1095336

\subsubsection{Perhitungan Menggunakan Metode Pohon Binomial dengan Program C++.}

Untuk melakukan perhitungan harga Opsi Beli dengan program $\mathrm{C++}$, pertama, buka program yang sudah dibuat. Program yang sama akan digunakan untuk kedua metode, sehingga harus dilakukan input angka "1" Pada tampilan awal program C++ seperti pada Gambar 1, untuk memilih perhitungan dengan metode Pohon Binomial.

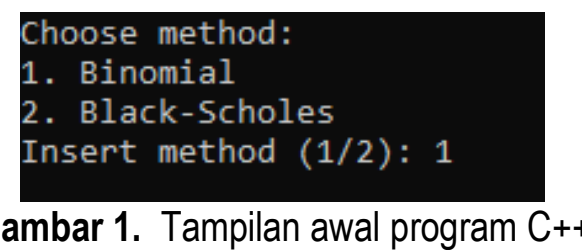

Lalu, harus dilakukan input data yang dibutuhkan, yaitu Current Stock Price $\left(S_{0}\right.$ sebesar 291.52, Strike Price $(K)=105$, Time to expiry $(t)=0,766871166$, Risk-free Interest Rate $(r)=1,56 \%$, dan Volatility $(\sigma)=0,300727$. Setelah semua data diinputkan, akan muncul Call Price sebagai output. Call Price adalah harga Opsi Beli yang dicari sebesar 187,11. Output program pada Gambar 2. 


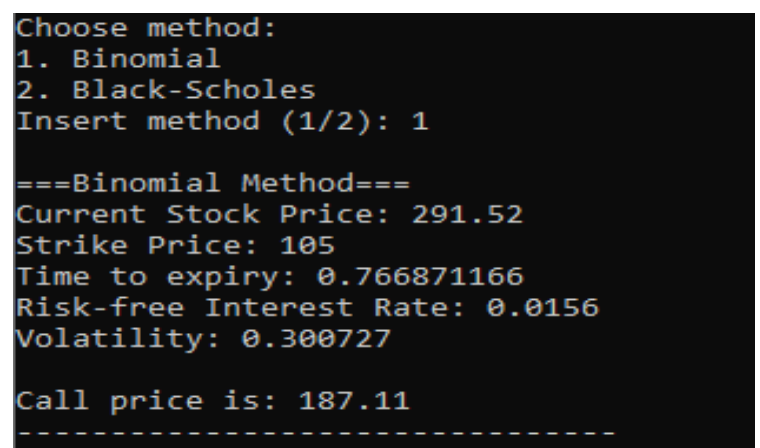

Gambar 2. Output program C++ untuk metode pohon binomial

\subsection{Perhitungan dengan Metode Black-Scholes}

\subsubsection{Perhitungan dengan Metode Black-Scholes dengan Microsoft Excel}

Untuk melakukan perhitungan dengan metode ini, pertama cari nilai dari $d 1$ dan $d 2$ dengan persamaan (13) dan (14). Hasil perhitungan disajikan dalam Tabel 6.

Tabel 6. Hasil perhitungan $d 1$ dan $d 2$

\begin{tabular}{cccc}
\hline$N$ & Close & $d 1$ & $d 2$ \\
\hline 0 & 157.919998 & 1.42322943 & 1.081186237 \\
1 & 142.190002 & 1.117481458 & 0.775963275 \\
$\vdots$ & $\vdots$ & $\vdots$ & $\vdots$ \\
249 & 289.799988 & 6.219062288 & 6.052829184 \\
250 & 291.519989 & 6.294213672 & 6.129063531 \\
\hline
\end{tabular}

Selanjutnya, cari nilai dari $N(d 1)$ dan $N(d 2)$ dengan bantuan NORM.DIST pada Microsoft Excel. Setelah didapat nilai $N(d 1)$ dan $N(d 2)$, lakukan perhitungan untuk harga Opsi Beli $(C)$ dengan persamaan (15). Hasil perhitungan disajikan pada Tabel 7.

Tabel 7. Hasil perhitungan $N(d 1), N(d 2)$, dan $C$

\begin{tabular}{cccc}
\hline$N$ & $N(d 1)$ & $N(d 2)$ & $C$ \\
\hline 0 & 0.922665172 & 0.860192861 & 57.19151106 \\
1 & 0.868105738 & 0.781114665 & 43.05253311 \\
$\vdots$ & $\vdots$ & $\vdots$ & $\vdots$ \\
249 & 1 & 1 & 185.299297 \\
250 & 1 & 1 & 187.0128287 \\
\hline
\end{tabular}

Dari Tabel 7 dapat dilihat pada $N=250$ nilai $C=187.0128287$ artinya pada saat hari ke- 250 , nilai harga Opsi Beli dengan Metode Black-Scholes adalah \$187.0128287.

\subsubsection{Perhitungan dengan Metode Black-Scholes dengan Program C++.}

Untuk melakukan perhitungan harga Opsi Beli dengan program $\mathrm{C++}$, pertama, buka program yang sudah dibuat. Kali ini, lakukan input angka "2" untuk memilih perhitungan dengan metode Black-Scholes. Tampilan awalnya program C++ pada Gambar 3.

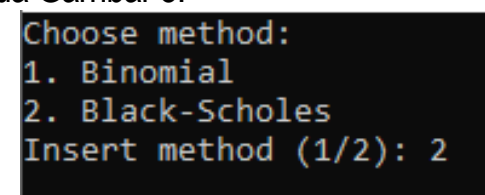

Gambar 3. Tampilan Awal Program C++

Lalu, dilakukan input data yang dibutuhkan, yaitu Current Stock Price $\left(S_{0}\right)$ sebesar 291.52, Strike Price $(K)=105$, Time to expiry $(t)=0,301587302$, Risk-free Interest Rate $(r)=1,56 \%$, dan Volatility $(\sigma)=300727$. Setelah semua data diinputkan, akan muncul Call Price sebagai output. Call Price adalah harga Opsi Beli yang dicari yaitu sebesar $\$ 187.013$. Output programnya pada Gambar 4. 


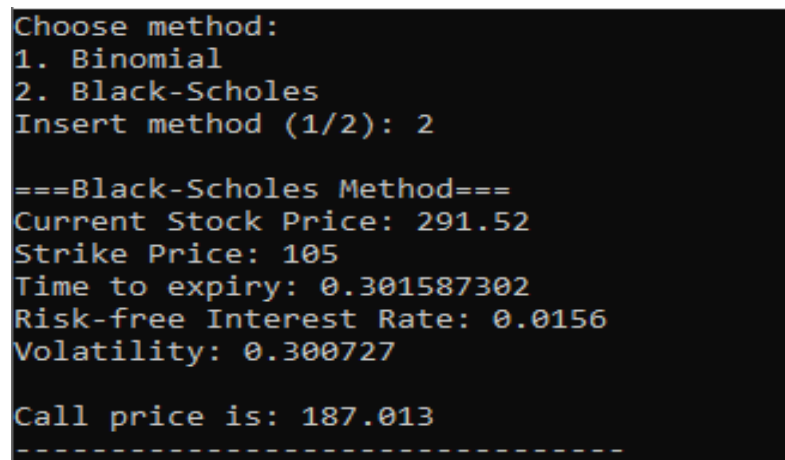

Gambar 4. Output program C++ untuk metode black-scholes

\section{KESIMPULAN}

Kesimpulan yang dapat diambil dari hasil pembahasan dalam perhitungan Harga Opsi Beli menggunakan Metode Pohon Binomial dan Metode Black-Scholes berturut-turut apabila dengan bantuan Microsoft Excel adalah $\$ 187.1095$, dan $\$ 187.0128$., sedangkan dengan bantuan program $\mathrm{C}++$, adalah \$187.11, dan \$187.013.

Dari harga-harga tersebut, dapat dilihat bahwa Harga Opsi Beli yang dihasilkan hampir sama, yaitu berkisar di \$187, baik itu menggunakan program $\mathrm{C}++$ atau dengan bantuan Microsoft Excel, oleh karena itu maka kedua metode tersebut dapat digunakan.

\section{REKOMENDASI}

Rekomendasi dari hasil penelitian ini, disarankan kepada Apple Inc. (AAPL) khususnya atau kepada perusahaan yang lainnya dalam penentuan Harga Opsi Beli dapat dipilih salah satu metode, apakah Metode Pohon Binomial atau Metode Black-Scholes. Selanjutnya gunakan metode yang lebih tinggi lagi misalnya metode Trinomial, multinomial, atau Crank Nicolson.

\section{UCAPAN TERIMAKASIH}

Ucapan Terima kasih penulis sampaikan kepada Direktorat Riset dan Pengabdian Masyarakat Direktorat Jenderal Riset dan Pengembangan Kementerian Riset, Teknologi, dan Pendidikan Tinggi yang telah mendanai penelitian ini melalui Penelitian Dasar Unggulan Perguruan Tinggi (PDUPT) tahun 2021 dengan nomor kontrak.1207/UN6_3.1/PT.00/2021

\section{DAFTAR PUSTAKA}

Cox, J. C., Ross, S. A., \& Rubinstein, M. (1979). Option pricing: a simplified approach. Journal of Financial Economics 7, 229-263.

Emmanuel, F. S., Adedoyin, A. O., \& Hammed, O. O. (2014). Performance measure of binomial model for pricing. Applied and Computational Mathematics, 3(6-1), 18-30. doi:10.11648/j.acm.s.2014030601.14

Hull, J. C. (2012). Options, Futures, and other derivatives (9th Edition). Pearson Education.

Krznaric, M. J. (2016). Comparison of option price from black-scholes. Model to actual values. Honors Research Projects. 396. http://ideaexchange.uakron.edu/honors_research_projects/396

Sulaiman, H., Hartono, W., \& Raharjo, J. F. (2017). Penerapan dari model matematika pengendalian persediaan barang (inventory model) pada system produksi di PD Handi Meubel Cirebon). Teorema: Teori dan Riset Matematika, 1(2), 11-24. 